Published in final edited form as:

Cancer Causes Control. 2013 January ; 24(1): 55-60. doi:10.1007/s10552-012-0089-5.

\title{
The association between cancer and amyotrophic lateral sclerosis
}

\author{
D. Michal Freedman, \\ Division of Cancer Epidemiology and Genetics, National Cancer Institute, NIH, DHHS, EPS \\ Room 7036, 6120 Exec. Blvd., Bethesda, MD 20892-7238, USA
}

Rochelle E. Curtis,

Division of Cancer Epidemiology and Genetics, National Cancer Institute, NIH, DHHS, EPS

Room 7042, 6120 Exec. Blvd., Bethesda, MD 20892-7238, USA

\section{Sarah E. Daugherty,}

Division of Cancer Epidemiology and Genetics, National Cancer Institute, NIH, DHHS, EPS

Room 8113, 6120 Exec. Blvd., Bethesda, MD 20892-7238, USA

\author{
James J. Goedert, \\ Division of Cancer Epidemiology and Genetics, National Cancer Institute, NIH, DHHS, EPS \\ Room 7068, 6120 Exec. Blvd., Bethesda, MD 20892-7238, USA
}

Ralph W. Kuncl, and

Department of Neurology, School of Medicine and Dentistry, University of Rochester, Rochester, NY, USA

\author{
Margaret A. Tucker \\ Division of Cancer Epidemiology and Genetics, National Cancer Institute, NIH, DHHS, EPS \\ Room 5058, 6120 Exec. Blvd., Bethesda, MD 20892-7238, USA \\ D. Michal Freedman: freedmam@mail.nih.gov
}

\section{Abstract}

Objective-Increasing evidence suggests that some neurodegenerative disorders, such as Parkinson's disease, are inversely related to cancer. Few epidemiologic studies have examined the relationship between cancer and amyotrophic lateral sclerosis (ALS), another major neurodegenerative disease. This study addresses that gap.

Methods-Using data from 16 population-based cancer registries of the Surveillance, Epidemiology, and End Results (SEER) Program of the U.S. National Cancer Institute and death certificates, we followed 2.7 million cancer survivors who were diagnosed between 1973 and 2007, and who survived at least 1 year following cancer diagnosis. The standardized mortality ratio (SMR) of observed to expected ALS deaths in cancer survivors was calculated.

Results-A total of 1,216 ALS deaths were reported among 1 year survivors of cancer over 16.6 million person-years of follow-up. ALS mortality was not significantly associated with the incidence of total cancers [SMR $=1.00$ (95\% confidence interval $(\mathrm{CI}), 0.95-1.06)$ ]. There was, however, a significantly elevated risk of ALS death among survivors of melanoma [SMR $=1.49$ $(95 \%(\mathrm{CI}), 1.17-1.85)]$ and of tongue cancer [SMR $=2.57(95 \% \mathrm{CI}, 1.41-4.32)]$, and a

(C) Springer Science+Business Media Dordrecht (outside the USA) 2012

Correspondence to: D. Michal Freedman, freedmamemail.nih.gov.

Conflict of interest None. 
significantly reduced ALS death risk among prostate cancer survivors [SMR $=0.86$ (95\% CI, 0.76-0.96)].

Conclusions-Cancer at certain sites may be related to risk of ALS death. Possible biologic factors linking ALS to these cancers are discussed. Future studies should attempt to confirm these associations using incident ALS outcomes. Establishing relationships between cancer and neurodegenerative diseases, such as ALS, opens new opportunities for understanding related pathophysiologic and therapeutic possibilities for these diseases.

\section{Keywords}

Amyotrophic lateral sclerosis; Neoplasms; Melanoma; Tongue neoplasms; Prostatic neoplasms

\section{Introduction}

Neurodegeneration and carcinogenesis appear to involve highly disparate pathophysiologic mechanisms-neurodegeneration results in irreversible cell death, whereas cells are resistant to death in carcinogenesis. Increasing evidence suggests that some neurodegenerative diseases such as Parkinson's disease (PD), and possibly Alzheimer's disease (AD), are inversely related to many cancers, but may have increased risk for certain other cancers [19]. Exploring the relationship between cancer and neurodegenerative diseases could provide new clues relevant to the etiologies and potential therapies for both sets of conditions.

Few epidemiologic studies have examined the relationship between cancer and amyotrophic lateral sclerosis (ALS), another major neurodegenerative disease [10-15]. ALS is a progressive disease characterized by degeneration of motor neurons that results in increasing weakness and death [16]. Survival is generally short, with about one-half dying 2-3 years after diagnosis [17-20], and only about 5-10\% surviving ten or more years [21]. Most studies of ALS and cancer have involved small numbers of subjects [12-15]. Thus, these studies have had insufficient statistical power to examine relationships between ALS and specific types of cancer.

The primary purpose of this study is to examine the relationship between ALS and total cancer as well as site-specific cancer in the National Cancer Institute (NCI) Surveillance, Epidemiology and End Results (SEER) Program. This study updates a prior SEER study of cancer and ALS [10]. The current study includes more than 2.7 million incident cancer cases and 1,216 deaths due to ALS, thus incorporating an additional 656 ALS deaths and extending follow-up by eight years. This study thus provides substantially greater statistical power to examine risk by specific cancer sites and allows analysis by time interval after cancer diagnosis, as well as by sex.

\section{Materials and methods}

We obtained cancer incidence data from the NCI's SEER Program from 1 January 1973 through 31 December 2007. Patient and population data were derived from the SEER 9 Registries Database (covering Connecticut, Hawaii, Iowa, New Mexico, Utah, Atlanta, Detroit, San Francisco-Oak-land, and Seattle-Puget Sound), three additional registries added in 1 January 1992 (Los Angeles, San-Jose Monterey, and Rural Georgia), and New Jersey, Kentucky, Louisiana, and Greater California, added to the SEER program in 2000. Data collected include primary tumor site, morphology, and stage of diagnosis. SEER registries follow patients annually for survival status. Cancer site categories were based on primary cancer site definitions, as used in the SEER monograph on New Malignancies among Cancer Survivors [22]. Only cancer sites in which there were 20 or more subsequent ALS deaths were included, with the exception of tongue cancer (with 14 ALS deaths), which was 
included because it had previously been associated with ALS mortality [10]. Although ALS affects all racial and ethnic groups, this study was limited to whites because of the small numbers of ALS deaths among other racial/ethnic groups in these registries. The Alaska registry was excluded because it is limited to American Indians/Alaskan Natives. The 16 remaining registries currently cover about $23 \%$ of the U.S. white population [http:// seer.cancer.gov/registries/data.html].

Quality assurance is maintained through on-site monitoring, data editing, case-finding audits, re-abstracting of cases, and various educational programs [23]. SEER has established a case ascertainment rate of $98 \%$, a follow-up rate of $95 \%$ [23], and overall microscopic diagnostic confirmation rate of more than $98 \%$.

Person-years at risk were accumulated for each subject beginning 1 year after cancer diagnosis to exclude the initial postdiagnosis period when the likelihood of reporting a cause of death other than cancer might compete with the cancer diagnosis. Person-years were counted until the date of death, date last known alive, date lost to follow-up, or 31 December 2007, whichever occurred first. Cause of death in SEER was provided by each state's vital records department.

We characterized observed deaths due to ALS (as an underlying cause of death) among subjects in the SEER database based on the classifications ICD-8 348.0, ICD-9 335.2, and ICD-10 G12.2. Although the latter two categories correspond to motor neuron disease (MND), ALS is the main subtype and accounts for about $90 \%$ of MND deaths [24].

The expected number of deaths from ALS was calculated by applying the 5 year age, 5 year calendar period, and sex-specific ALS mortality rate in the SEER registry regions to the person-years at risk for each type of cancer diagnosis in the SEER database. The total observed $(\mathrm{O})$ and expected numbers of ALS deaths for each stratum were then totaled. We calculated the standardized mortality ratio (SMR) for each cancer site as the ratio of the observed number of ALS deaths to the expected number of deaths and calculated exact (two-sided) $95 \%$ confidence intervals (CI), assuming a Poisson distribution of the observed deaths.

ALS mortality risks were also analyzed over three time intervals following cancer diagnosis, that is, 1-4 years; 5-9 years; and $\geq 10$ years, to allow additional examination of the likelihood that ALS diagnosis preceded the cancer diagnosis. Risks by cancer site were also analyzed separately by sex.

\section{Results}

A total of 1,216 ALS deaths were reported among 1 year survivors of cancer over 16.6 million person-years of follow-up, including 7.5 million person-years in men and 9.1 million in women. The average duration of follow-up was 6.1 years.

Among survivors of all types of cancer combined, the risk of death due to ALS was not increased $[\mathrm{SMR}=1.00(95 \% \mathrm{CI}=0.95-1.06)]$ (Table 1). There were, however, relationships between ALS mortality risk and specific cancer diagnoses. ALS deaths in persons with melanoma were significantly increased [SMR $=1.49(O=78,95 \% \mathrm{CI}=1.17-$ 1.85)] (Table 1). The mortality risk was elevated in each of the time intervals after cancer diagnosis, and the total ALS mortality risk for melanoma was nearly identical in men ( $O=$ $50, \mathrm{SMR}=1.49)$ and in women $(O=28, \mathrm{SMR}=1.48)($ Table 2$)$. There was no apparent difference in risk by melanoma histology, but only 43 subjects died of ALS with an identified melanoma histology (data not shown), so the opportunity to examine risk by histology was limited. 
The risk of ALS death was also significantly elevated after tongue cancer ( $86 \%$ of which were squamous cell carcinomas) $[\mathrm{SMR}=2.57(95 \% \mathrm{CI}=1.41-4.32)]$ (Table 1). Here, too, the risk was elevated in each of the time intervals after cancer diagnosis, and the risks were similar in men and women (SMR $=2.37$ vs. 3.03 , respectively) (Table 2 ). When tongue cancer was grouped with other oral cancers, there was no statistically significant relationship between combined oral squamous cell carcinomas (i.e., cancers of the tongue, gum, and mouth) and risk of ALS death (data not shown).

The only cancer site inversely associated with ALS death was prostate cancer, with an overall risk of ALS death of $0.86(O=289,95 \% \mathrm{CI}=0.76-0.96)($ Table 1$)$. The inverse association was strengthened as time from cancer diagnosis increased. When we stratified prostate cancer cases before and after the introduction of PSA screening [25], we found similar inverse associations with ALS death in both strata: $₫ 987, \mathrm{SMR}=0.81(O=42,95$ $\% \mathrm{CI}=0.58-1.09) ;[1987, \mathrm{SMR}=0.87(O=247,95 \% \mathrm{CI}=0.76-0.98)$.

\section{Discussion}

In this SEER database with more than 16 million person-years of follow-up after a primary cancer, we found that ALS mortality risk was significantly elevated for survivors of melanoma and of tongue cancer. We also observed a significantly inverse association between prostate cancer and ALS death. ALS mortality was not associated with total cancer incidence. These results are consistent with the earlier results reported for ALS mortality after cancer based on the more limited SEER data [10]. In the earlier report, we also found no overall association between cancer and ALS, but did find adverse associations with melanoma and tongue cancer and a nonsignificant suggestion of an inverse association with prostate cancer. The much larger numbers of events in the current study permit greater precision in the results, the power to identify the significant inverse association with prostate cancer, as well as the opportunity to investigate the consistency of associations by gender and across time intervals.

The elevated ALS risk associated with melanoma has previously been observed in Australia $[11,26]$. The pattern of SMR's by period of time after melanoma diagnosis indicates that the adverse association persists long after the melanoma diagnosis and is comparable in both genders, thus adding to the evidence that the two diseases are associated. In general, adverse associations in relation to subsequent ALS mortality (such as for melanoma and also tongue cancer) may suggest factors that elevate or decrease risks for both the cancer and ALS, or, alternatively, could indicate an effect of cancer therapy on ALS risk.

Although speculative, one possible etiologic link between the disorders relates to the role of metabotropic glutamate receptors. Glutamate, a major neurotransmitter in mammals, and its receptors have been implicated in neurodegenerative pathology, including that of ALS [27]. Riluzole, which is the only drug approved by U.S. Food and Drug Administration for ALS treatment [27], has been shown to interfere with signaling from mGluR1 [28], one type of metabotropic glutamate receptor. Glutamate receptor subunits are expressed in several tumors, including melanoma [29]. In a study of human melanoma biopsy samples, ectopic expression of mGluR1 was identified in $60 \%$ of samples, but not in normal skin [28, 30]. A preliminary trial of riluzole and advanced melanoma found that in several patients riluzole suppressed metabolic activity and inhibited signaling through the MAPK and p13/AKT pathways in vivo [31]. Although a phase II trial showed no Response Evaluation Criteria in Solid Tumors (RECIST), there was a suggestion of modest antitumor activity [28]. Cavalheiro and Olney [32] speculate that if glutamate signaling plays a role in carcinogenesis, other glutamate antagonist drugs that have been found unsuitable for treating neuropsychiatric conditions may become therapeutic alternatives for some cancers. 
ALS is a disease of relatively selective motor neuron vulnerability, but there has been evidence of cutaneous changes that coincide with neurodegeneration. These changes do not appear to be a secondary consequence of the weight loss and muscular atrophy accompanying the disease process [33-36]. Investigators have noted skin changes in the amount and characteristics of collagen [33-36] and increased expression of neurotrophic factors, such as insulin-like growth factor 1 (IGF-1) [33-36], as well as vascular endothelial growth factor (VEGF) [33], transactivation-responsive DNA-binding protein-43 (TDP-43) [33], progranulin [33], and hepatocyte growth factor (HGF) [36]. Some of these, such as HGF, may be related to both neuronal survival [36] and tumorigenesis. [37] These cutaneous changes, particularly involving growth factors, suggest there may be other connections between melanoma and ALS.

The risk of ALS was also elevated following tongue cancer, and the relationship was not limited to the first few years after cancer diagnosis, although the number of cases for each time period was small. As with melanoma, glutamate receptor expression has been observed in oral squamous cell carcinoma [29, 38]. However, the absence of a relationship between ALS death and combined oral squamous cell carcinomas does not support a glutamate receptor connection. It is uncertain whether unidentified factors or possibly chance accounts for the tongue cancer/ ALS relationship.

The inverse relationship observed between prostate cancer and ALS was strengthened as time from prostate cancer diagnosis to ALS death lengthened. The likelihood that the cancer competes with ALS as a cause of death should decrease, not increase, over time from cancer diagnosis. Moreover, while more indolent prostate cancer cases would be expected in the PSA era, we found little difference in the inverse association between pre- and post-PSA eras, suggesting that competing causes of death due to a prostate cancer diagnosis in the prePSA era would not likely account fully for the inverse association observed.

As a general matter, if the inverse association with prostate cancer is real, the relationship would suggest one of the following: a factor(s) that elevates prostate cancer risk and that lowers ALS risk; a factor(s) that reduces risk for prostate cancer and increases ALS risk; or a treatment(s) modality for prostate cancer that is protective against ALS. For example, one potential mechanism involves IGF-1, which is a putative risk factor for prostate cancer [2, $39,40]$, and has been under investigation for its possible therapeutic/protective effects on ALS [41]. IGF-1 is a growth regulator that plays a role in cell proliferation and inhibits apoptosis of prostate cancer cells [39]. Although clinical trials of IGF-1 have been largely negative for ALS [41, 42], benefits were seen in organotypic [43] and transgenic ALS mouse models and continue to be of therapeutic interest [41].

Among our study's strengths are its large size, with more than 2.7 million cancer cases, 1,206 deaths due to ALS, and more than 16 million person-years of follow-up. By using SEER registries, we also ensured comprehensive and unbiased ascertainment of cancer cases.

The study's chief limitation is its reliance on death certificates, not incidence data, for ALS outcomes. Because ALS is generally rapidly fatal, with a median survival of about $2-3$ years from diagnosis [17], death certificates are often used as surrogates for incidence data in epidemiology [44]. Studies have found that death certificates accurately identify ALS or motor neuron disease in 70-90\% of ALS cases [44]. Moreover, expected ALS case numbers were based on ALS mortality rates in the general population, which were also derived from death certificates. To the extent that the misclassification was nondifferential between cancer subjects and the general population, the effect would be to diminish the magnitude and significance of both adverse and inverse associations. If, however, a prior 
cancer diagnosis competes with ALS as a cause of death on the death certificate, the effect could bias associations downward. Thus, the underreporting of ALS would reduce the likelihood of false-positive results, but would undermine detecting true-positive associations as well.

By relying on death certificates for ALS outcomes, we could not evaluate prospectively the relationship between cancer and ALS diagnosis. However, the data allowed review of risk relationships where the cancer diagnoses preceded death by five or even $\geq 10$ years, whichgiven the generally short survival of persons with ALS - reduced substantially the number of ALS diagnoses that likely preceded the cancer determinations. Another limitation is the lack of information regarding potential confounders, but insofar as there are few known risk factors for ALS (aside from age and gender, which were accounted for), the limitation is largely theoretical. Also, because we examined associations between multiple cancer sites and ALS mortality, our results should be interpreted with caution.

In summary, our study found a significantly elevated risk of ALS death among survivors of melanoma and survivors of tongue cancer, and these risks remained elevated across time intervals. We also found a significant inverse relationship between prostate cancer and ALS mortality. Future studies should attempt to confirm these associations using incident ALS outcomes. Establishing relationships between cancer and neurodegenerative disease such as ALS, which were previously thought to be unrelated, opens up new opportunities for understanding shared or related pathophysiologic processes and therapeutic possibilities across disease categories.

\section{Acknowledgments}

This research was supported by the Intramural Research Program of the National Institutes of Health, National Cancer Institute, and the U.S. Public Health Service of the Department of Health and Human Services. We thank Jeremy Miller of Information Management Services, Inc. for biomedical computer assistance and Dr. Robert J. Biggar of Queensland University of Technology for his helpful comments.

\section{References}

1. Plun-Favreau H, Lewis PA, Hardy J, Martins LM, Wood NW. Cancer and neurodegeneration: between the devil and the deep blue sea. PLoS Genet. 2010; 6:e1001257. [PubMed: 21203498]

2. Tabares-Seisdedos R, Dumont N, Baudot A, et al. No paradox, no progress: inverse cancer comorbidity in people with other complex diseases. Lancet Oncol. 2011; 12:604-608. [PubMed: 21498115]

3. Devine MJ, Plun-Favreau H, Wood NW. Parkinson's disease and cancer: two wars, one front. Nat Rev Cancer. 2011; 11:812-823. [PubMed: 22020207]

4. Roe CM, Fitzpatrick AL, Xiong C, et al. Cancer linked to Alzheimer disease but not vascular dementia. Neurology. 2010; 74:106-112. [PubMed: 20032288]

5. Bajaj A, Driver JA, Schernhammer ES. Parkinson's disease and cancer risk: a systematic review and meta-analysis. Cancer Causes Control. 2010; 21:697-707. [PubMed: 20054708]

6. Olsen JH, Friis S, Frederiksen K, McLaughlin JK, Mellemkjaer L, Moller H. Atypical cancer pattern in patients with Parkinson's disease. Br J Cancer. 2005; 92:201-205. [PubMed: 15583688]

7. Driver JA, Logroscino G, Buring JE, Gaziano JM, Kurth T. A prospective cohort study of cancer incidence following the diagnosis of Parkinson's disease. Cancer Epidemiol Biomarkers Prev. 2007; 16:1260-1265. [PubMed: 17548694]

8. Driver JA, Beiser A, Au R, et al. Inverse association between cancer and Alzheimer's disease: results from the Framingham Heart Study. BMJ. 2012; 344:e1442. [PubMed: 22411920]

9. Olsen JH, Friis S, Frederiksen K. Malignant melanoma and other types of cancer preceding Parkinson disease. Epidemiology. 2006; 17:582-587. [PubMed: 16837822] 
10. Freedman DM, Travis LB, Gridley G, Kuncl RW. Amyotrophic lateral sclerosis mortality in 1.9 million US cancer survivors. Neuroepidemiology. 2005; 25:176-180. [PubMed: 16103728]

11. Baade PD, Fritschi L, Freedman DM. Mortality due to amyotrophic lateral sclerosis and Parkinson's disease among melanoma patients. Neuroepidemiology. 2007; 28:16-20. [PubMed: 17164565]

12. Zisfein J, Caroscio JT. No association of amyotrophic lateral sclerosis with cancer. Mt Sinai J Med. 1988; 55:159-161. [PubMed: 3260344]

13. Chio A, Brignolio F, Meineri P, Rosso MG, Tribolo A, Schiffer D. Motor neuron disease and malignancies: results of a population-based study. J Neurol. 1988; 235:374-375. [PubMed: 3171620]

14. Kurtzke JF, Beebe GW. Epidemiology of amyotrophic lateral sclerosis: 1. A case-control comparison based on ALS deaths. Neurology. 1980; 30:453-462. [PubMed: 7189251]

15. Kondo K. Motor neuron disease and Parkinson's disease are not associated with other disorders at autopsy. Neuroepidemiology. 1984; 3:182-194.

16. Rowland LP, Shneider NA. Amyotrophic lateral sclerosis. N Engl J Med. 2001; 344:1688-1700. [PubMed: 11386269]

17. Kiernan MC, Vucic S, Cheah BC, et al. Amyotrophic lateral sclerosis. Lancet. 2011; 377:942-955. [PubMed: 21296405]

18. Logroscino G, Traynor BJ, Hardiman O, et al. Descriptive epidemiology of amyotrophic lateral sclerosis: new evidence and unsolved issues. J Neurol Neurosurg Psychiatry. 2008; 79:6-11. [PubMed: 18079297]

19. Steenland K, MacNeil J, Seals R, Levey A. Factors affecting survival of patients with neurodegenerative disease. Neuroepidemiology. 2010; 35:28-35. [PubMed: 20389122]

20. Mateen FJ, Carone M, Sorenson EJ. Patients who survive 5 years or more with ALS in Olmsted County, 1925-2004. J Neurol Neurosurg Psychiatry. 2010; 81:1144-1146. [PubMed: 20627966]

21. Chio A, Logroscino G, Hardiman O, et al. Prognostic factors in ALS: a critical review. Amyotroph Lateral Scler. 2009; 10:310-323. [PubMed: 19922118]

22. Curtis, RE.; Freedman, DM.; Ron, E.; Ries, LAG.; Hacker, DG.; Edwards, BK.; Tucker, MA.; Fraumeni, JF, Jr. New malignancies among cancer survivors: SEER cancer registries, 1973-2000. National Cancer Institute; Bethesda: 2006.

23. Swan J, Wingo P, Clive R, et al. Cancer surveillance in the U.S.: can we have a national system? Cancer. 1998; 83:1282-1291. [PubMed: 9762927]

24. Leone M, Chandra V, Schoenberg BS. Motor neuron disease in the United States, 1971 and 19731978: patterns of mortality and associated conditions at the time of death. Neurology. 1987; 37:1339-1343. [PubMed: 3614653]

25. Barry MJ. Clinical practice. Prostate-specific-antigen testing for early diagnosis of prostate cancer. N Engl J Med. 2001; 344:1373-1377. [PubMed: 11333995]

26. Baade PD, Herrero Hernandez E, Freedman DM, Smithers BM, Fritschi L. No role for melanoma treatment in the association between melanoma and amyotrophic lateral sclerosis or Parkinson's disease. Neuroepidemiology. 2010; 35:303-304. [PubMed: 20962539]

27. Habib AA, Mitsumoto H. Emerging drugs for amyotrophic lateral sclerosis. Expert Opin Emerg Drugs. 2011; 16:537-558. [PubMed: 21806316]

28. Lee HJ, Wall BA, Wangari-Talbot J, et al. Glutamatergic pathway targeting in melanoma: singleagent and combinatorial therapies. Clin Cancer Res. 2011; 17:7080-7092. [PubMed: 21844014]

29. Stepulak A, Luksch H, Gebhardt C, et al. Expression of glutamate receptor subunits in human cancers. Histochem Cell Biol. 2009; 132:435-445. [PubMed: 19526364]

30. Speyer CL, Smith JS, Banda M, Devries JA, Mekani T, Gorski DH. Metabotropic glutamate receptor-1: a potential therapeutic target for the treatment of breast cancer. Breast Cancer Res Treat. 2012; 132:565-573. [PubMed: 21681448]

31. Yip D, Le MN, Chan JL, et al. A phase 0 trial of riluzole in patients with resectable stage III and IV melanoma. Clin Cancer Res. 2009; 15:3896-3902. [PubMed: 19458050]

32. Cavalheiro EA, Olney JW. Glutamate antagonists: deadly liaisons with cancer. Proc Natl Acad Sci USA. 2001; 98:5947-5948. [PubMed: 11371628] 
33. Yasui K, Oketa Y, Higashida K, Fukazawa H, Ono S. Increased progranulin in the skin of amyotrophic lateral sclerosis: an immunohistochemical study. J Neurol Sci. 2011; 309:110-114. [PubMed: 21802097]

34. Watanabe T, Okeda Y, Yamano T, Ono S. An immunohistochemical study of ubiquitin in the skin of sporadic amyotrophic lateral sclerosis. J Neurol Sci. 2010; 298:52-56. [PubMed: 20850799]

35. Suzuki M, Mikami H, Watanabe T, et al. Increased expression of TDP-43 in the skin of amyotrophic lateral sclerosis. Acta Neurol Scand. 2010; 122:367-372. [PubMed: 20175762]

36. Nomura M, Oketa Y, Yasui K, Ishikawa H, Ono S. Expression of hepatocyte growth factor in the skin of amyotrophic lateral sclerosis. Acta Neurol Scand. 2012; 125:389-397. [PubMed: 21824113]

37. Bogenrieder T, Herlyn M. The molecular pathology of cutaneous melanoma. Cancer Biomark. 2010; 9:267-286. [PubMed: 22112480]

38. Park SY, Lee SA, Han IH, et al. Clinical significance of metabotropic glutamate receptor 5 expression in oral squamous cell carcinoma. Oncol Rep. 2007; 17:81-87. [PubMed: 17143482]

39. Kasper JS, Liu Y, Giovannucci E. Diabetes mellitus and risk of prostate cancer in the health professionals follow-up study. Int J Cancer. 2009; 124:1398-1403. [PubMed: 19058180]

40. Rowlands MA, Gunnell D, Harris R, Vatten LJ, Holly JM, Martin RM. Circulating insulin-like growth factor peptides and prostate cancer risk: a systematic review and meta-analysis. Int $\mathrm{J}$ Cancer. 2009; 124:2416-2429. [PubMed: 19142965]

41. Sakowski SA, Schuyler AD, Feldman EL. Insulin-like growth factor-I for the treatment of amyotrophic lateral sclerosis. Amyotroph Lateral Scler. 2009; 10:63-73. [PubMed: 18608100]

42. Sorenson EJ, Windbank AJ, Mandrekar JN, et al. Subcutaneous IGF-1 is not beneficial in 2-year ALS trial. Neurology. 2008; 71:1770-1775. [PubMed: 19029516]

43. Bilak MM, Kuncl RW. Delayed application of IGF-I and GDNF can rescue already injured postnatal motor neurons. NeuroReport. 2001; 12:2531-2535. [PubMed: 11496143]

44. Marin B, Couratier P, Preux PM, Logroscino G. Can mortality data be used to estimate amyotrophic lateral sclerosis incidence? Neuroepidemiology. 2011; 36:29-38. [PubMed: 21088432] 
